\title{
Left Ventricular torsion rates by CMR correlate with invasively-derived hemodynamic data in pediatric pulmonary hypertension
}

\author{
Melanie J Dufva ${ }^{1 *}$, Uyen Truong ${ }^{1,2}$, Robin Shandas ${ }^{1,2}$, Vitaly Kheyfets ${ }^{1,2}$ \\ From 19th Annual SCMR Scientific Sessions \\ Los Angeles, CA, USA. 27-30 January 2016
}

\section{Background}

Pulmonary hypertension $(\mathrm{PH})$ is a progressive disease that results in right ventricular dysfunction through increased resistive afterload and pulmonary arterial (PA) stiffening. The ventricles are connected at the interventricular sulcus, share an interlaced network of muscle fibers, and are hemodynamically dependent upon each other via the interventricular septum (IVS). Thus, the left ventricle (LV) plays a major role in RV contractile performance and may also be affected in this disease via ventricular-ventricular interaction. The relationship between hemodynamic parameters and torsion rate is unknown. We hypothesized that LV torsion rate is reduced in pediatric $\mathrm{PH}$ and is concomitant with hemodynamic markers of $\mathrm{PH}$, and that this is due to the impact of prolonged increased impedance, resulting in reduced RV performance.

\section{Methods}

Tagged cine CMR images were acquired for 8 pediatric $\mathrm{PH}$ patients and 18 control-matched subjects. LV systolic torsion rate (TR) was quantified using harmonic phase analysis. Right heart catheterization and echocardiography was performed on PH patients. Vascular ventricular coupling (VVC) was estimated with the single beat pressure-volume method and calculated as the ratio of arterial elastance to ventricular end systolic elastance (contractility).

\section{Results}

LV TR was significantly reduced in PH patients compared to control patients $(\mathrm{TR}=1.61 \pm 0.890 /$ systolic cycle

Bioengineering, University of Colorado Denver, Denver, CO, USA Full list of author information is available at the end of the article versus $3.04 \pm 1.480 /$ systolic cycle, $\mathrm{p}=0.0189)$. LV TR correlated highly with mean pulmonary arterial pressure (mPAP, $r=0.93, p=0.0008)$, RV systolic pressure $(r=$ $0.94, \mathrm{p}=0.0005)$, and pulmonary vascular resistance (PVR, $r=0.93, p=0.0010)$. VVC correlated highly with LV TR $(r=0.85, p=0.0071)$, as did RV contractility $(\mathrm{r}=0.86, \mathrm{p}=0.0063)$.

\section{Conclusions}

Pediatric PH patients have reduced LV torsion rates compared to those of healthy patients, which could be significantly reducing RV contractile performance. Also, LV TR is strongly related to RV contractility and hemodynamic parameters derived by catheterization.

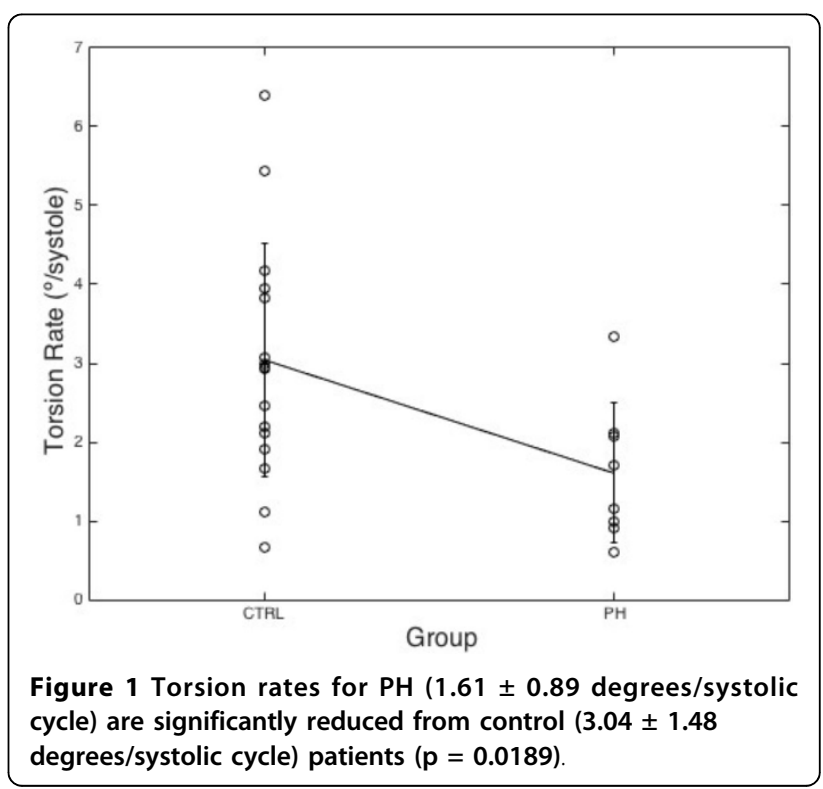




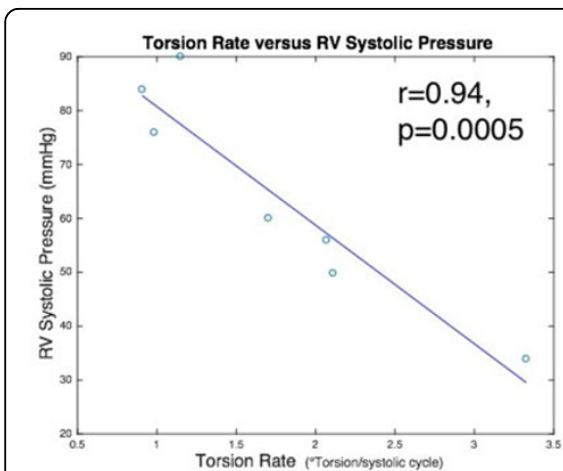

a)

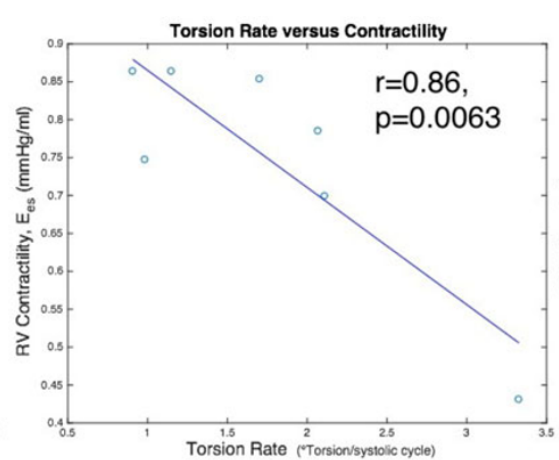

b)

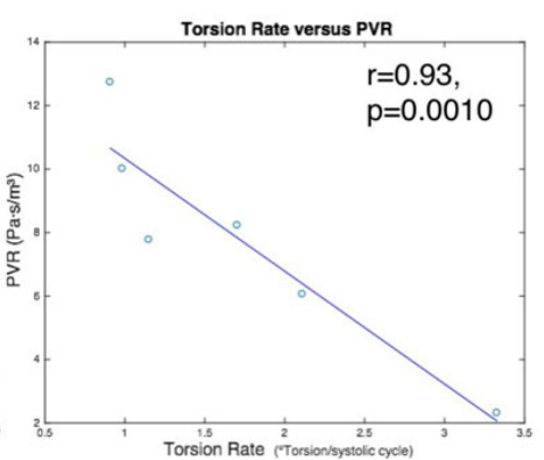

c)

Figure 2 Torsion rates for PH patients are highly correlated with a) RV systolic pressure $(r=0.94, p=0.0005)$, b) RV contractility ( $r=$ $0.86, p=0.0063)$, and $c)$ PVR $(r=0.93, p=0.0010)$.

\section{Authors' details}

${ }^{1}$ Bioengineering, University of Colorado Denver, Denver, CO, USA.

${ }^{2}$ Cardiology, Children's Hospital Colorado, Aurora, CO, USA.

Published: 27 January 2016

doi:10.1186/1532-429X-18-S1-P4

Cite this article as: Dufva et al.: Left Ventricular torsion rates by CMR correlate with invasively-derived hemodynamic data in pediatric pulmonary hypertension. Journal of Cardiovascular Magnetic Resonance 2016 18(Suppl 1):P4.

Submit your next manuscript to BioMed Central and take full advantage of:

- Convenient online submission

- Thorough peer review

- No space constraints or color figure charges

- Immediate publication on acceptance

- Inclusion in PubMed, CAS, Scopus and Google Scholar

- Research which is freely available for redistribution

Submit your manuscript at www.biomedcentral.com/submit
C Biomed Central 